Thorax, 1981, 36, 29-37

\title{
Use of lung pressure-volume curves and helium-sulphur hexafluoride washout to detect emphysema in subjects with mild airflow obstruction
}

\author{
R PETRIK PEREIRA, D HUNTER, AND N B PRIDE \\ From the Department of Medicine, Royal Postgraduate Medical School, Hammersmith Hospital, \\ London
}

ABSTRACT Mild abnormalities of peripheral lung function can be detected by simple methods, but it remains difficult to determine when these changes are the result of emphysema rather than disease of the airways. We have compared the value of measurements of lung distensibility and a multibreath test of helium ( $\mathrm{He}$ ) and sulphur hexafluoride $\left(\mathrm{SF}_{6}\right)$ washout in distinguishing between six men with mild impairment of airway function caused by asthma (group A) and six men with similar airway function but probable widespread emphysema (group E). In group $\mathrm{E}$ there were striking abnormalities in the static pressure-volume curve of the lungs (reduced lung recoil pressures, increased chord compliance, increased shape factor) and the relation between maximum expiratory flow and lung recoil pressure fell within the normal range. In group A there were only minor abnormalities in lung distensibility and maximum expiratory flow was reduced at a standard lung recoil pressure. In addition carbon monoxide transfer coefficient was reduced in group $\mathrm{E}$ but normal in group $\mathrm{A}$. Normal values for $\mathrm{He}-\mathrm{SF}_{6}$ washout were similar to those previously described. Differences in $\mathrm{He}-\mathrm{SF}_{6}$ washout between group $\mathrm{A}$ and group $\mathrm{E}$ men were small and in part accounted for by differences in functional residual capacity. In subjects with lung disease, end-tidal $\mathrm{He}$ and $\mathrm{SF}_{6}$ concentrations during washout were erratic and it was sometimes impossible to define a crossover point. We conclude that in our hands this technique is less useful for detecting acinar disease than are measurements of lung distensibility or carbon monoxide transfer. Considerable changes in lung distensibility may occur at an early stage in the natural history of emphysema and are readily distinguishable from the small changes that occur in mild asthma.

In recent years several new methods have been developed for detecting mild abnormalities of peripheral lung function in epidemiological surveys. Such abnormalities may be caused by smoking-related disease of the peripheral airways, by emphysema, or by asthma-conditions which have different responses to treatment and different prognoses. But it remains difficult to diagnose emphysema by simple tests. The best indicators of emphysema are thought to be the static pressurevolume (PV) curve of the lung and the single breath carbon monoxide transfer (TLCO). ${ }^{1}$ Neither test is truly specific for emphysema as changes in the PV curve can occur in asthma ${ }^{2}$ and TLCO is slightly reduced in young smokers ${ }^{3}$ at an age when anatomical emphysema is extremely rare. ${ }^{45}$ But probably the most severe abnormalities in both tests occur when there is severe emphysema. $\mathrm{Re}$ cently von Nieding et $a l^{6}$ have claimed that by comparing the washout after equilibration of two poorly soluble gases of different molecular mass, helium $(\mathrm{He})$ and sulphur hexafluoride $\left(\mathrm{SF}_{6}\right)$, they can distinguish between parallel inhomogeneities in ventilatory efficiency caused by airway obstruction and serial inhomogeneities caused by incomplete gas diffusion. Incomplete gas diffusion will delay washout of a gas of large mass $\left(\mathrm{SF}_{6}\right)$ relatively more than that of a gas of low mass (He) so the cumulative expired volume at which endtidal $\mathrm{He}$ becomes less than end-tidal $\mathrm{SF}_{6}$ ("crossover volume"), which is small in normal subjects, becomes larger if there is serial inhomogeneity. 
Von Nieding et $a l^{6}$ found that patients believed to have emphysema had crossover volumes six to seven times larger than in normal subjects or patients with asthma or bronchitis. They attributed this abnormality to enlargement of the peripheral airspaces (acini), and suggested that $\mathrm{He}_{-} \mathrm{SF}_{6}$ washout could provide a specific indication of emphysema.

In a study of intermediate alpha ${ }_{1}$-antitrypsin deficiency we found abnormalities of the PV curve and of $\mathrm{He}_{-} \mathrm{SF}_{6}$ washout in some men suggesting the presence of emphysema. ${ }^{7}$ In the present study we have examined $\mathrm{He}_{-} \mathrm{SF}_{6}$ washout in 23 normal subjects and have examined changes in lung distensibility and in $\mathrm{He}_{-} \mathrm{SF}_{6}$ washout in six men with mild asthma and in six men with radiological or functional evidence of widespread emphysema or both and a similar mild abnormality of airway function. We have compared the distinction provided between the two groups of patients by $\mathrm{He}_{-} \mathrm{SF}_{6}$ washout and by the PV curve of the lungs.

\section{Subjects}

We compared six men with probable emphysema and mild abnormality of airway function (group E) with six men with comparable abnormality of airway function caused by asthma (group A) (table 1).

Three of the six men chosen for group $E$ had definite radiographic changes of widespread em- physema. These men were referred to hospital because of persistent bronchial infection (subject $\frac{}{C}$ 2), acute pneumothorax (subject 3), and to confirm 을 the diagnosis of homozygous alpha ${ }_{1}$-antitrypsin $\frac{\text { p }}{\vec{D}}$ deficiency (subject 4). Subject 1 was found to have $\stackrel{\varnothing}{\varnothing}$

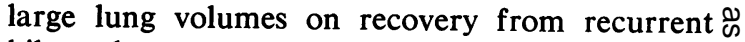
bilateral pneumothoraces; further investigation $\vec{\circ}$ showed that he had intermediate alpha ${ }_{1}$-antitrypsin deficiency (Pi MZ) but the chest radiograph did $\vec{\omega}$ not show definite evidence of emphysema. The remaining two subjects ( 5 and 6 ) were selected $x$ from men studied during a survey of working men in West London ${ }^{8}$ because their total lung capacity $\overrightarrow{.}$ (TLC) was more than 2 SD above the mean, and the carbon monoxide transfer coefficient was more 을 than 2 SD below the mean for non-smokers in this survey. Both men had persistent cough but their chest radiographs were normal. All the subjects in group $\mathrm{E}$ were current or ex-smokers and none showed a significant response to bronchodilator treatment. Because we chose subjects with probable emphysema but without gross abnormalities of airway function the subjects in group E are not typical of patients with generalised emphysema. Indeed it was difficult to identify such subjects because they do not normally have symptoms requiring referral to hospital, while definite radiological changes of emphysema are found only rarely in surveys of working men. ${ }^{9}$

The six men with asthma were all attending the asthma clinic at this hospital and had been

Table 1 Clinical details of subjects studied

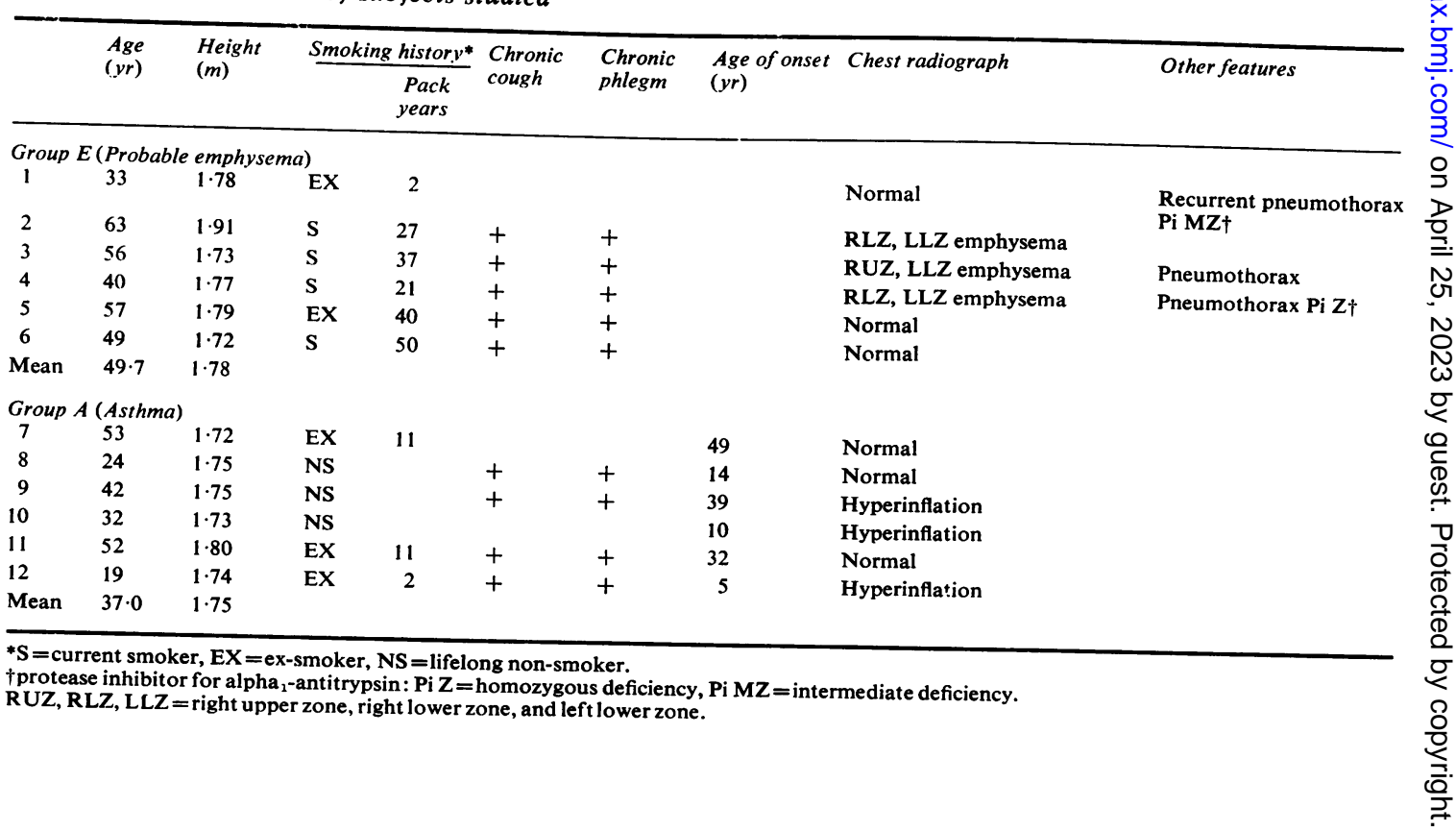


observed to show considerable variation in spirometry. None was a current smoker. Chest radiographs showed large volume lungs in three subjects.

To establish normal values for $\mathrm{He}_{-} \mathrm{SF}_{6}$ washout we studied 23 subjects (five smokers of 10 or less cigarettes/day, 13 lifelong non-smokers, and five ex-smokers) aged between 25 and 49 years. None had respiratory symptoms and all had normal spirometry (forced expiratory volume in one second $\left(\mathrm{FEV}_{1}\right)$ averaging $113 \%$ of predicted values). ${ }^{10}$

\section{Methods}

Spirometry was performed using a dry spirometer (Garw Electronic Instruments Ltd). The best of three measurements of $\mathrm{FEV}_{1}$ and of slow vital capacity (VC) were recorded. Total lung capacity (TLC), functional residual capacity (FRC), and residual volume (RV) were measured by the Boyle's law technique ${ }^{11}$ in an integrated flow, pressure-corrected body plethysmograph. ${ }^{12}$ Maximum expiratory flow-volume (MEFV) curves were recorded with the subject seated in the plethysmograph and breathing out to atmosphere through a Fleisch no 4 pneumotachograph coupled to a Sanborn 270 different pressure transducer. Flow and change in thoracic gas volume were displayed un a Tektronix storage oscilloscope with hard copy unit, and from the tracings peak expiratory flow (PEF) and maximum flow when $50 \%$ and $25 \%$ of VC remained to be expired $\left(\operatorname{Vmax}_{50}\right.$ and $\left.\operatorname{Vmax}_{25}\right)$ were read. TLCo was measured by the technique of Ogilvie et al. ${ }^{13}$ The mean of two measurements was taken and the results were also expressed per litre of alveolar volume (TLCO/ $\mathrm{VA}_{\mathrm{A}}$, alveolar volume being calculated from the single breath dilution of helium and expressed at
BTPS.

Static expiratory PV curves were obtained with the subject seated in a variable-volume body plethysmograph ${ }^{14}$ using the oesophageal balloon technique. ${ }^{15}$ A $10 \mathrm{~cm}$ balloon was passed into the oesophagus so that the tip was $42-45 \mathrm{~cm}$ from the external nares and the difference between mouth and oesophageal pressure (transpulmonary pressure) was measured with a Sanborn 267 differential pressure transducer. Each deflation manoeuvre was preceded by three slow full inflations. A balloon volume of $0.5 \mathrm{ml}$ was used and checked periodically during the procedure. Mean PV curves were constructed by drawing the line of best fit through the points from at least three expirations. Maximum transpulmonary pressure was recorded as the highest pressure sustained for two to three seconds at full inflation. From the PV curve we calculated static expiratory compliance (chord compliance between FRC and FRC $+500 \mathrm{ml}$ ), specific compliance (compliance/FRC) and static transpulmonary pressure (Pst(1)) at $70 \%$ predicted TLC and $60 \%$ TLC. The shape factor, $\mathrm{k}$, of the PV curve was obtained by fitting an exponential function to the original PV points by an iterative, least-squares computerised technique. ${ }^{16} 17$ Maximum flow-static recoil curves were constructed from the PV curves and the MEFV curves; conductance upstream from the equal pressure points during forced expiration ( $V \max / \mathrm{Pst}(1))$ was calculated at FRC. ${ }^{18}$

Simultaneous multiple breath washout of $\mathrm{He}$ and $\mathrm{SF}_{6}$ was performed using the technique of von Nieding et al. ${ }^{6}$ With the subject seated the washin of a mixture of $10 \% \mathrm{SF}_{6}$ and $5 \% \mathrm{He}$ (remaining gases $22 \% \mathrm{O}_{2}, 63 \% \mathrm{~N}_{2}$ ) was continued until the difference between inspired and end-tidal $\mathrm{He}$ and $\mathrm{SF}_{6}$ concentrations was small and constant. The subject was then allowed to inspire room air via a gas meter which recorded volume, while end-tidal concentrations of $\mathrm{He}$ and $\mathrm{SF}_{6}$ were measured using a mass spectrometer (MS4X, AEI Scientific Apparatus) and were recorded as a percentage of the end-tidal concentration at the end of the washin period. Tidal volume was maintained nearly constant throughout the procedure. Washout curves were analysed by measuring the cumulative expired volume to the point at which the $\mathrm{He}$ concentration equalled the $\mathrm{SF}_{6}$ concentration $\left(\mathrm{He}-\mathrm{SF}_{6}\right.$ crossover volume, $\left.\mathrm{COV}\right)$ and to the point at which the $\mathrm{SF}_{6}$ concentration reached $1 \%$ (cumulative expired volume to $1 \%$, CEV $1 \%$ ) of the equilibrated value at the end of washin. ${ }^{67}$ Both volumes were expressed also as a ratio of FRC to allow for differences in lung size. Stepwise dilution of $\mathrm{He}$ and $\mathrm{SF}_{6}$ did not reveal any alinearity of the mass spectrometer.

In group A measurements of spirometry, MEFV curves, lung volumes, and PV curves were made both before and after inhalation of $200 \mu \mathrm{gm}$ of salbutamol from a pressurised aerosol. The measurements of $\mathrm{He}_{-} \mathrm{SF}_{6}$ washout were made in group A after treatment with salbutamol.

\section{Results}

SPIROMETRY AND MAXIMUM EXPIRATORY

FLOW-VOLUME CURVES (table 2)

In general, airway function in group $\mathrm{E}$ was similar to that in group A after bronchodilator treatment, although the $\mathrm{FEV}_{1} / \mathrm{VC}$ ratio was lower in group 
Table 2 Results of spirometry, maximum flow-volume curves, lung volumes, and CO transfer

\begin{tabular}{|c|c|c|c|c|c|c|c|}
\hline & \multicolumn{2}{|c|}{ Group $E$} & \multicolumn{4}{|c|}{ Group A } & \multirow{3}{*}{$\begin{array}{l}\text { p } \\
\text { E versus } A \\
\text { (before bd) }\end{array}$} \\
\hline & \multirow[t]{2}{*}{ Mean } & \multirow[t]{2}{*}{$S E$} & \multicolumn{2}{|c|}{ Before bd $d^{*}$} & \multicolumn{2}{|c|}{ After bd } & \\
\hline & & & Mean & $S E$ & Mean & $S E$ & \\
\hline $\begin{array}{l}\mathrm{FEV}_{1}(\mathrm{l}) \\
\% \text { predicted } \\
\text { vC (l) } \\
\% \text { predicted }\end{array}$ & $\begin{array}{c}2 \cdot 85 \\
77 \cdot 8 \\
5 \cdot 03 \\
112 \cdot 0\end{array}$ & $\begin{array}{l}(0.48) \\
(10 \cdot 5) \\
(0.34) \\
(5.3)\end{array}$ & $\begin{array}{c}2 \cdot 32 \\
60 \cdot 8 \\
4 \cdot 20 \\
89 \cdot 9\end{array}$ & $\begin{array}{l}(0 \cdot 20) \\
(5.9) \\
(0 \cdot 27) \\
(6 \cdot 0)\end{array}$ & $\begin{array}{c}2 \cdot 88 \\
75 \cdot 4 \\
4 \cdot 68 \\
99 \cdot 3\end{array}$ & $\begin{array}{l}(0 \cdot 25) \\
(6 \cdot 8) \\
(0 \cdot 33) \\
(6 \cdot 7)\end{array}$ & $\begin{array}{l}0 \cdot 33 \\
0 \cdot 19 \\
0 \cdot 70 \\
0 \cdot 03\end{array}$ \\
\hline 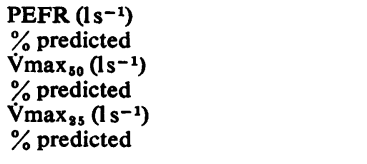 & $\begin{array}{c}7 \cdot 53 \\
82 \cdot 3 \\
2 \cdot 11 \\
39 \cdot 2 \\
0 \cdot 90 \\
33 \cdot 2\end{array}$ & $\begin{array}{l}(0.48) \\
(5 \cdot 2) \\
(0.67) \\
(11 \cdot 1) \\
(0.45) \\
(12 \cdot 8)\end{array}$ & $\begin{array}{c}6 \cdot 52 \\
70 \cdot 8 \\
2 \cdot 27 \\
39 \cdot 0 \\
0 \cdot 65 \\
22 \cdot 0\end{array}$ & $\begin{array}{l}(0 \cdot 62) \\
(7 \cdot 1) \\
(0 \cdot 20) \\
(4 \cdot 5) \\
(0 \cdot 10) \\
(2 \cdot 7)\end{array}$ & $\begin{array}{c}8 \cdot 02 \\
87 \cdot 2 \\
2.93 \\
50 \cdot 7 \\
0.97 \\
31 \cdot 0\end{array}$ & $\begin{array}{l}(0 \cdot 67) \\
(8 \cdot 4) \\
(0 \cdot 42) \\
(7 \cdot 6) \\
(0 \cdot 20) \\
(5 \cdot 7)\end{array}$ & $\begin{array}{l}0.22 \\
0.22 \\
0.82 \\
0.99 \\
0 \cdot 60 \\
0.42\end{array}$ \\
\hline $\begin{array}{l}\text { TLC (l) } \\
\% \text { predicted }\end{array}$ & $\begin{array}{r}9 \cdot 2 \\
133 \cdot 3\end{array}$ & $\begin{array}{l}(0.6) \\
(5 \cdot 2)\end{array}$ & $\begin{array}{r}7 \cdot 4 \\
109 \cdot 7\end{array}$ & $\begin{array}{l}(0.5) \\
(5 \cdot 5)\end{array}$ & $\begin{array}{r}7 \cdot 2 \\
106 \cdot 5\end{array}$ & $\begin{array}{l}(0 \cdot 4) \\
(4 \cdot 1)\end{array}$ & $\begin{array}{l}0.08 \\
0.01\end{array}$ \\
\hline $\begin{array}{l}\text { FRC (I) } \\
\% \text { predicted }\end{array}$ & $\begin{array}{r}6 \cdot 2 \\
140 \cdot 5\end{array}$ & $\left(\begin{array}{l}0.4) \\
(4 \cdot 7)\end{array}\right.$ & $\begin{array}{r}4 \cdot 6 \\
126 \cdot 0\end{array}$ & $\begin{array}{l}(0 \cdot 5) \\
(16 \cdot 2)\end{array}$ & $\begin{array}{r}4 \cdot 2 \\
113 \cdot 3\end{array}$ & $\begin{array}{l}(0 \cdot 2) \\
(7 \cdot 8)\end{array}$ & $\begin{array}{l}0.06 \\
0.22\end{array}$ \\
\hline FRC/TLC \% & $68 \cdot 3$ & $(2 \cdot 1)$ & $61 \cdot 8$ & ( 3.4$)$ & $55 \cdot 5$ & $(3 \cdot 1)$ & $0 \cdot 21$ \\
\hline RV/TLC \% & $44 \cdot 5$ & $(2 \cdot 2)$ & $43 \cdot 0$ & $(2 \cdot 8)$ & $35 \cdot 2$ & $(2 \cdot 0)$ & 0.68 \\
\hline $\begin{array}{l}\text { TLco }\left(\operatorname{mmol} \min ^{-1} \mathrm{kPa}^{-1}\right) \\
\% \text { predicted }\end{array}$ & $\begin{array}{r}6 \cdot 3 \\
62 \cdot 0\end{array}$ & $\begin{array}{l}(1 \cdot 09) \\
(8 \cdot 7)\end{array}$ & $\begin{array}{r}11 \cdot 4 \\
105 \cdot 0\end{array}$ & $\begin{array}{l}(0.81) \\
(8.9)\end{array}$ & $\overline{-}$ & & $\begin{array}{l}0.004 \\
0.004\end{array}$ \\
\hline $\begin{array}{l}\text { TLco/VA }\left(\mathrm{mmol} \mathrm{min}-1 \mathrm{kPa}^{-1} \mathrm{l}^{-1}\right) \\
\% \text { predicted }\end{array}$ & $\begin{array}{r}0.99 \\
66.0 \\
\end{array}$ & $\begin{array}{l}(0 \cdot 13) \\
(7 \cdot 5)\end{array}$ & $\begin{array}{r}1 \cdot 84 \\
108 \cdot 0\end{array}$ & $\begin{array}{l}(0.09) \\
(5.4)\end{array}$ & - & & $\begin{array}{r}<0.001 \\
0.001\end{array}$ \\
\hline
\end{tabular}

Sources of predicted values: FEV $_{1}$ (10); FRC, VC, TLC(19); PEFR, $\dot{V}_{\max }$, Vmax $_{25}$ (20); TLCO, TLCO/VA (21).

*bd = bronchodilator.

E, reflecting the larger VC. Both groups showed curvilinearity of MEFV curves (convex to the volume axis) so that maximum flow at small lung volumes was proportionately more reduced than PEF.

LUNG VOLUMES (table 2)

Three of the subjects in group E were selected because of a large TLC and this is reflected in the large mean value for the group. The FRC/ TLC ratio was also larger in group $E$ than group $A$, but despite the difference in lung size, RV/TLC was similar in group $\mathrm{E}$ and group $\mathrm{A}$ (before bronchodilator treatment) because VC was above average predicted values in group $\mathrm{E}$.

CARBON MONOXIDE TRANSFER (table 2)

There were highly significant differences between the two groups in TLCO and TlCo/VA. Two of the subjects in group $E$ were selected because they had a reduced TLCo/VA but there was complete separation between the two groups, with individual values in group A ranging from 93$125 \%$ of predicted and in group E from $34-83 \%$ of predicted.

LUNG DISTENSIBILITY (figs 1 and 2)

The PV curves of five of the six group E subjects were displaced to larger volumes and lower values of Pst(1) compared with the curves in group A.
There were highly significant differences in all the indices derived from these curves (table 3 ). In group $\mathrm{E}$ the shape factor (k) was increased (average $220 \%$ of expected value) and Pst(1) was re- $\frac{2}{\varnothing}$ duced at all lung volumes. The PV curves and values of $\mathbf{k}$ in group A were mainly within or just above the upper limits of the normal range before bronchodilators. Treatment with bronchodilators slightly reduced chord compliance, $\mathrm{k}$ and Pst(1) at all volumes.

MAXIMUM FLOW-STATIC RECOIL CURVES

The relation between Vmax and Pst(l) fell within the normal range in group $\mathrm{E}$ although the $\mathrm{Vmax} / \mathrm{\delta}$ Pst(1) slope tended to be abnormally steep. In group A, Vmax at a given Pst(1) was greatly re- 0 duced before bronchodilator but increased considerably after treatment (fig 3 ).

CHANGES AFTER BRONCHODILATOR TREATMENT IN GROUP A

All measurements of airway function $\left(\mathrm{FEV}_{1}, \stackrel{\mathrm{N}}{\mathrm{N}}\right.$ $\mathrm{FEV}_{1} / \mathrm{VC}, \mathrm{PEF}, \mathrm{Vmax}_{50}, \mathrm{Vmax}_{25}$, maximum flowstatic recoil curves, and upstream conductance) were improved after bronchodilators (fig 3, table $\overline{\mathbb{D}}$ 2). In addition there were decreases in $\mathrm{RV}$ and $\stackrel{?}{\rightarrow}$ FRC; although there was a slight decrease in mean 0 TLC this was less than the fall in RV so VC rose. There was a slight reduction in $\mathrm{k}$ and chord compliance (fig 2, table 3). 


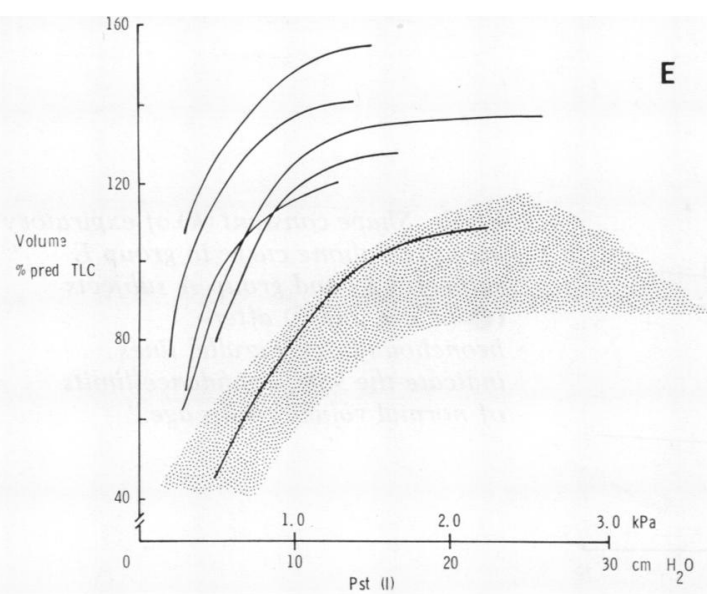

(a)

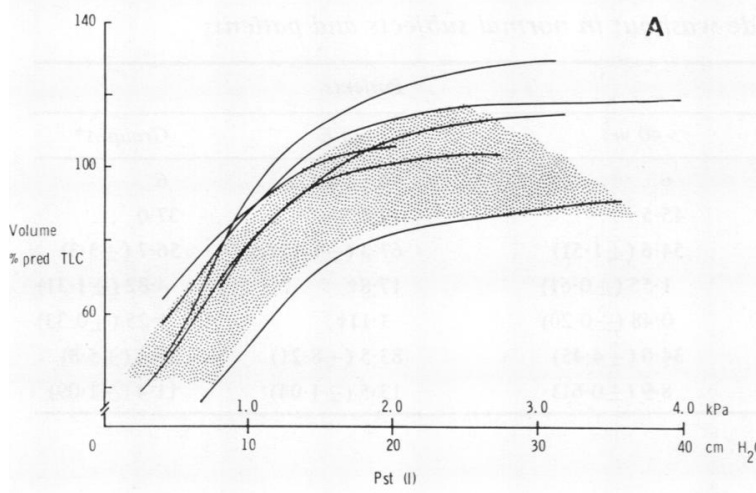

(b)

Fig 1 Expiratory static pressure-volume curves of the lung. (a) Group A subjects (before bronchodilator); (b) group E subjects. Volume expressed as a percentage of predicted TLC. Shaded area shows normal range of values in asymptomatic subjects in our laboratory.
$\mathrm{He}_{\mathrm{S}} \mathrm{SF}_{6}$ washouT (table 4)

In eight of the 23 normal subjects $\mathrm{COV}$ was zero, end-tidal He concentration being equal to or lower than the end tidal $\mathrm{SF}_{6}$ concentration from the start of washout. In the 15 subjects in whom COV was greater than zero, crossover took place in the first few breaths and the largest value was 3.8 1 . There was a slight increase (not statistically significant) in COV and COV/FRC with age but little change in CEV $1 \%$. Eighteen of the 23 normal subjects were studied on two occasions, usually on separate days; repeatability of CEV $1 \%$ and CEV $1 \% /$ FRC was relatively good (mean difference between first and second measurements $2 \cdot 11$ and 0.64 respectively) but was proportionately worse for the small values of COV/FRC (mean difference 0.23 ). Two normal subjects were studied on four or five occasions and the average coefficient of variation was $8.6 \%$ for CEV $1 \%, 8.8 \%$ for CEV $1 \% / F R C$ but $72 \%$ for COV/FRC.

In both groups $\mathrm{E}$ and $\mathrm{A} \mathrm{CEV} 1 \%$ was increased compared with normal subjects. Although CEV $1 \%$ was larger in group $E$ than in group $A$, this difference was almost completely removed when the larger FRC was taken into account. Crossover volume could be defined in only four of the six group $E$ subjects, in all of whom it was enlarged $(10 \cdot 1,10 \cdot 5,22 \cdot 6$, and 27.91$)$; in the other two group $\mathrm{E}$ subjects end-tidal concentrations of $\mathrm{He}$ and $\mathrm{SF}_{6}$ fluctuated and there were several crossover points. Mean $\mathrm{COV}$ in the group A subjects was slightly increased above normal values but the largest value was $8 \cdot 41$.

\section{Discussion}

The main purpose of our study was to compare $\mathrm{He}_{-} \mathrm{SF}_{6}$ washout with established methods for distinguishing between patients with intrinsic airway disease and with emphysema. Unfortunately differ-

Table 3 Mean values ( \pm SEM) of indices of lung distensibility

\begin{tabular}{|c|c|c|c|c|c|c|c|}
\hline & \multicolumn{2}{|c|}{ Group E } & \multicolumn{4}{|l|}{ Group A } & \multirow{3}{*}{$\begin{array}{l}\text { p value, Group } E \\
\text { versus group } A \\
\text { (before bd) }\end{array}$} \\
\hline & \multirow[t]{2}{*}{ Mean } & \multirow[t]{2}{*}{$S E M$} & \multicolumn{2}{|c|}{ Before $b d$} & \multicolumn{2}{|c|}{ After bd } & \\
\hline & & & Mean & $S E M$ & Mean & $S E M$ & \\
\hline Expiratory compliance $\left(1 \mathrm{kPa}^{-1}\right)$ & $8.07 \pm$ & $0 \cdot 78$ & $3 \cdot 65 \pm$ & $0 \cdot 26$ & $3 \cdot 32 \pm$ & $0 \cdot 17$ & $<0.001$ \\
\hline Specific compliance $\left(\mathrm{kPa}^{-1}\right)$ & $1.32 \pm$ & $0 \cdot 11$ & $0.83 \pm$ & 0.08 & $0 \cdot 78 \pm$ & 0.05 & 0.005 \\
\hline Pst (1) at TLC ( $\mathrm{kPa})$ & $1 \cdot 60 \pm$ & $0 \cdot 18$ & $3 \cdot 18 \pm$ & 0.34 & $2 \cdot 84 \pm$ & 0.35 & 0.002 \\
\hline Pst (1) at $70 \%$ predicted TLC $(\mathrm{kPa})$ & $0.42 \pm$ & 0.09 & $0.83 \pm$ & $0 \cdot 12$ & $0.75 \pm$ & 0.09 & 0.025 \\
\hline Pst (1) at $60 \% \mathrm{TLC}(\mathrm{kPa})$ & $0.43 \pm$ & 0.07 & $0.74 \pm$ & 0.09 & $0.61 \pm$ & 0.06 & 0.027 \\
\hline $\mathrm{k}\left(\mathrm{kPa}^{-1}\right)$ & $2 \cdot 51 \pm$ & 0.18 & $1.47 \pm$ & 0.08 & $1.29 \pm$ & $0 \cdot 10$ & $<0.001$ \\
\hline
\end{tabular}




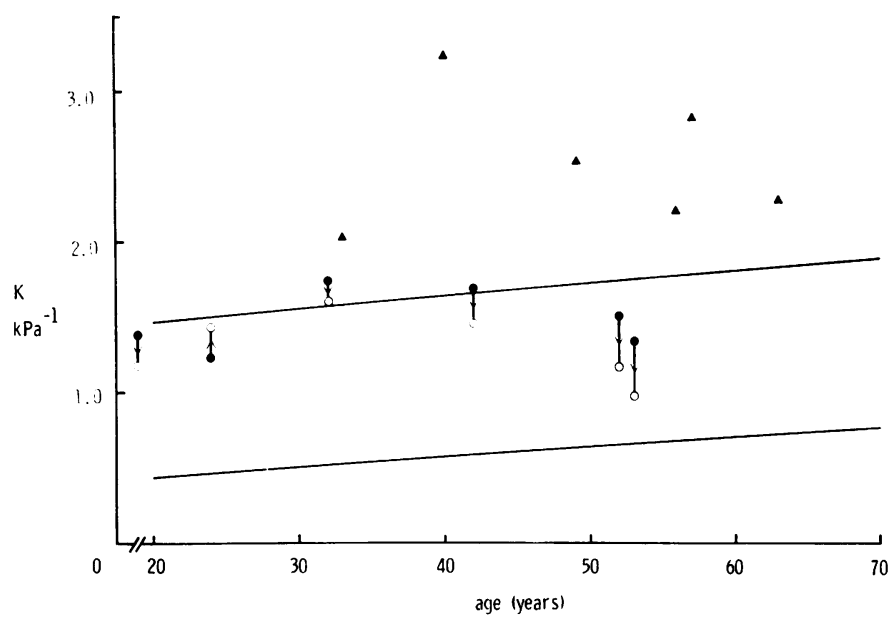

Fig 2 Shape constant ( $k$ ) of expiratory pressure-volume curve in group $E$ subjects $(\mathbf{\Lambda})$ and group $A$ subjects $(O$ before and $\bigcirc$ afterbronchodilator). Parallel lines indicate the $95 \%$ confidence limits of normal values versus age. ${ }^{17}$

Table 4 Results (+SEM) of helium-sulphur hexafluoride washout in normal subjects and patients

\begin{tabular}{|c|c|c|c|c|c|}
\hline & \multicolumn{3}{|l|}{ Normal subjects } & \multicolumn{2}{|l|}{ Patients } \\
\hline & $<30 y r$ & $30-39 y r$ & $>40 y r$ & Group E & Group $A^{*}$ \\
\hline Number of subjects & 10 & 7 & 6 & 6 & 6 \\
\hline Mean age (yr) & $27 \cdot 3$ & $34 \cdot 0$ & $45 \cdot 5$ & $49 \cdot 7$ & $37 \cdot 0$ \\
\hline FRC/TLC $\%$ & $53 \cdot 3( \pm 1 \cdot 78)$ & $55 \cdot 5( \pm 2 \cdot 03)$ & $54 \cdot 6( \pm 1 \cdot 51)$ & $67 \cdot 3( \pm 1 \cdot 17)$ & $56 \cdot 7( \pm 3 \cdot 3)$ \\
\hline $\operatorname{cov}(\mathrm{l})$ & $0.63( \pm 0.25)$ & $1.19( \pm 0.53)$ & $1 \cdot 55( \pm 0.61)$ & $17 \cdot 8 \dagger$ & $4.82( \pm 1.31)$ \\
\hline COV/FRC & $0.19( \pm 0.07)$ & $0.32( \pm 0.14)$ & $0.48( \pm 0.20)$ & $3 \cdot 11 \dagger$ & $1.25( \pm 0.33)$ \\
\hline CEV $1 \% \mathrm{SF}_{6}$ (l) & $27 \cdot 7( \pm 2 \cdot 78)$ & $28 \cdot 7( \pm 1 \cdot 66)$ & $34 \cdot 0( \pm 4 \cdot 45)$ & $83 \cdot 5( \pm 8 \cdot 21)$ & $46 \cdot 4( \pm 5 \cdot 8)$ \\
\hline CEV $1 \% \mathrm{SF}_{\mathrm{g}} / \mathrm{FRC}$ & $9.0( \pm 0.51)$ & $8 \cdot 3( \pm 0.49)$ & $8.9( \pm 0.61)$ & $13 \cdot 5( \pm 1 \cdot 04)$ & $11.4( \pm 1.09)$ \\
\hline
\end{tabular}

*Asthmatic subjects were studied after bronchodilator treatment.

† Mean values for the four subjects in whom a COV was measured.

ences in $\mathrm{He}_{-} \mathrm{SF}_{6}$ washout proved to be much less clear-cut than differences in lung distensibility or carbon monoxide transfer.

Our conclusions depend critically on whether our group E patients did indeed have widespread emphysema, which is notoriously difficult to diagnose at an early stage during life. Three patients had obvious bilateral radiological signs of emphysema, while the other three were selected by functional changes (enlarged TLC and reduced TLCo/VA) which are associated with emphysema at postmortem. ${ }^{22}$ Our selection criteria were subsequently confirmed by the measurements of lung distensibility, which in all six group $\mathrm{E}$ subjects showed the abnormalities associated with emphysema (reduction in lung recoil pressures and increase in chord compliance). The mildest functional changes were in subject 1 whose PV curve lay within the normal range (fig $1 b$ ), but even in this man values of chord compliance and $k$ were abnormal and TLCo/VA was only $77 \%$ of the predicted value. It is more difficult to define whether the group $\mathrm{E}$ men also had intrinsic narrowing of the airways. Five of the six men had chronic cough and expectoration but this reflects mucus production in large airways, whereas intrinsic airway disease leading to airflow obstruc- $\rightarrow$ tion is located in bronchi of less than $2-3 \mathrm{~mm}$. diameter. ${ }^{23}$ Tests of peripheral lung function such $N$ as the single breath $\mathrm{N}_{2}$ test, frequency dependence $\mathrm{N}$ of compliance, $\operatorname{Vmax}_{25}$, and closing volume may $\mathrm{N}$ be affected both by loss of lung recoil and by $\omega$ disease of the small airways. However the relation betwen Vmax and Pst(1) fell in the normal range

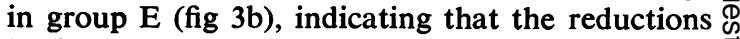
in Vmax could be explained solely by changes in the PV curve. In the group A subjects carbon monoxide transfer was normal and indices of lung $\underset{\mathbb{D}}{ }$ distensibility were only slightly abnormal so it $\stackrel{\odot}{\overparen{D}}$ seems reasonable to attribute almost all the reduc- $\unrhd$ tion in airway function to intrinsic airway disease. By conventional clinical, radiological, and func- 


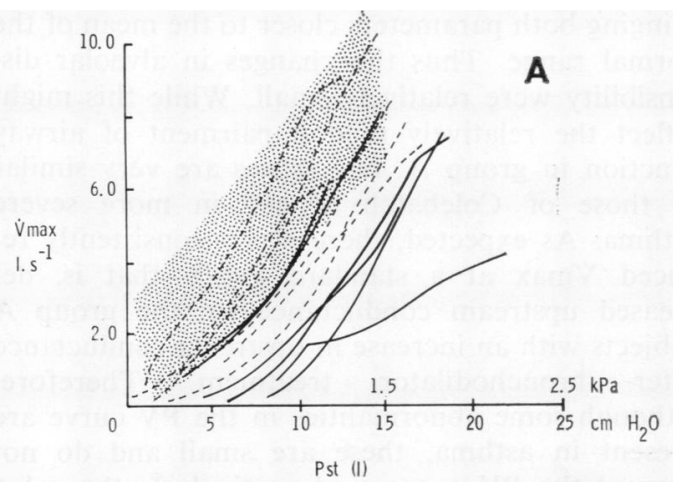

(a)

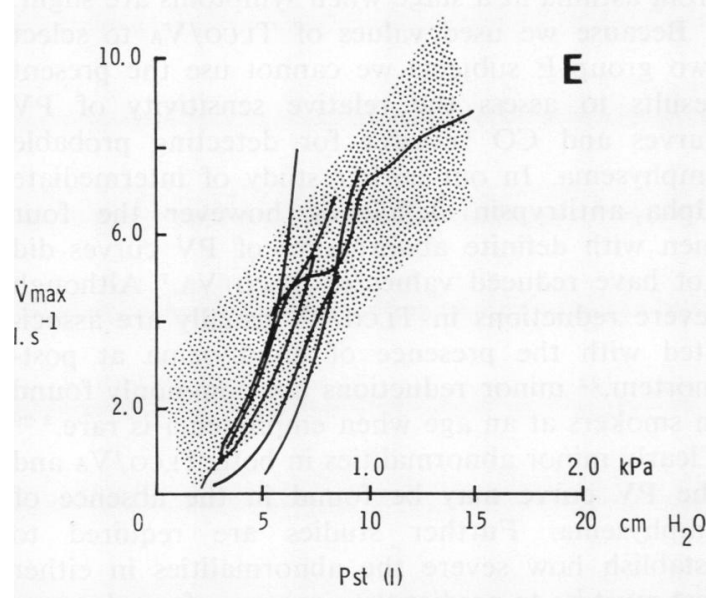

(b)

Fig 3 Relation between maximum expiratory flow ( $(\dot{V}$ max) and static lung recoil pressure (Pst (I)).

(a) Subjects of group A before (solid lines) and after (dashed lines) bronchodilator; (b) group E subjects. Shaded area shows normal range of values in asymptomatic subjects in our laboratory.

tional criteria therefore group A had intrinsic airway disease without significant acinar disease, whereas in group $\mathrm{E}$ there was considerable evidence of acinar disease, which was sufficient to account for the observed reduction in Vmax.

Despite these clear differences in mechanical properties and carbon monoxide transfer between groups $\mathrm{A}$ and $\mathrm{E}$, differences in $\mathrm{He}_{-} \mathrm{SF}_{6}$ washout were disappointingly small. In normal subjects our values of CEV $1 \%$ were similar to (but slightly smaller than) those previously reported ${ }^{6}$ and repeatability was relatively good. But the crossover point occurred very early in washout in normal subjects, so that a difference of one breath on a repeat run made a large proportional difference in $\mathrm{COV}$; sometimes expired $\mathrm{SF}_{6}$ exceeded expired He from the very first breath. In subjects with lung disease our results were again qualitatively similar to those of von Nieding $e^{t} a^{6}$ with an increase in CEV $1 \%$ in groups $\mathrm{A}$ and $\mathrm{E}$ compared with normal subjects, a slight increase in $\mathrm{COV}$ in group $\mathrm{A}$, and a larger increase (in those subjects in whom it could be measured) in group $\mathrm{E}$, but all these changes were smaller in our subjects. The criteria for diagnosing emphysema used by von Nieding et $a l^{6}$ differed from ours and although their patients had lower mean values of $\mathrm{FEV}_{1}(1.251)$ they also had much lower mean values of FRC (3.05 1) and of TLC (4.64 1) so that it is difficult to predict what the combined effect of these functional differences would be on the $\mathrm{He}-\mathrm{SF}_{6}$ washout. But we have not found more striking results in studies of other patients with more severe airflow obstruction outside the present series.

The test was more difficult to apply in subjects with lung disease. Even when there is an alveolar plateau for $\mathrm{He}$ and $\mathrm{SF}_{6}$ concentrations, resolution is critical because the ratio of end-tidal $\mathrm{He}$ and $\mathrm{SF}_{6}$ concentrations changes rather slowly over a number of breaths. In some patients end-tidal concentrations of $\mathrm{He}$ and $\mathrm{SF}_{6}$ did not decrease smoothly during washout, so that the two gas concentrations could cross over more than once. In disease expired $\mathrm{He}$ and $\mathrm{SF}_{6}$ rise throughout expiration so absolute values of end-tidal concentrations (and because of differences in the shapes of the concentration-time curves for the two gases, ${ }^{6}$ potentially also the ratio of the two concentrations) are sensitive to variations in expired time and volume. Variations in expired volume or flow also might result in parallel slow and fast spaces making slightly varying contributions to successive expirations, so accounting for irregularities in end-tidal values. Hence tidal breathing during washout in patients probably has to be more regular than in normal subjects to produce consistent changes in end-tidal gas concentrations. Other more complex techniques for quantifying the differential washout of $\mathrm{He}$ and $\mathrm{SF}_{6}$ may avoid some of these problems. ${ }^{24}$ But the theoretical requirements for a test that can detect the specific ventilation inhomogeneity of emphysema are demanding. Presumably the dilatation of terminal airspaces in emphysema impairs serial diffusion of gas; this has to be distinguished from abnormality caused by parallel inhomogeneities which will inevitably coexist because of the non-uniformity of emphysematous changes. Furthermore, a suc- 
cessful test would have to distinguish between the serial inhomogeneity that occurs because of emphysematous dilatation of the terminal bronchiole (centri-acinar) or the whole acinus (panacinar), and the serial inhomogeneity that may arise in pure airway disease from sequential ventilation of alveoli with obstructed airways via collateral pathways to adjacent, unobstructed alveoli.

In contrast with the findings with $\mathrm{He}_{-} \mathrm{SF}_{\mathrm{g}}$ washout, the abnormalities of lung distensibility in group E were unexpectedly large, the increases in $\mathbf{k}$ being similar to those we have previously observed in subjects disabled by severe emphysema. ${ }^{17}$ Recently we have also found increased $k$ values in some asymptomatic subjects with intermediate alpha ${ }_{1}$-antitrypsin deficiency, again suggesting that changes in the PV curve may develop at an early stage in the natural history of emphysema. ${ }^{7} \mathrm{Be}-$ cause Pst(1) is an important determinant of airway dimensions and the driving pressure for Vmax, changes in Vmax might be expected to parallel changes in Pst(1). But in the men with intermediate alpha $_{1}$-antitrypsin deficiency and abnormal PV curves, ${ }^{7}$ Vmax at a given Pst(l) was actually greater than in normal men of similar age, resembling the change that occurs with aging. ${ }^{25}$ In the present group E subjects, although the relation between Vmax and Pst(1) fell within the normal range, $V \max /$ Pst(l) slopes again were steeper than normal. In patients with severe disability and emphysema, however, Vmax is almost always reduced at a given Pst(l). ${ }^{26}$ These results suggest that changes in lung distensibility (and by implication emphysema) may precede any abnormality of the airways. We believe the large VC in group $\mathrm{E}$ men may similarly reflect an early stage in the natural history of emphysema in which changes in lung distensibility allowing TLC to increase, outweigh the tendency to enhanced airway closure and increase in RV. Although unusual, values of VC in emphysema above predicted values have been reported previously. ${ }^{27}$

Conventional analysis of the PV curve in asthma is complicated by the changes in RV, FRC, and sometimes TLC that occur as the severity of asthma varies. The exponential analysis provides size-independent parameters of the shape $(k)$ and the position (Vo/Vmax) of the curve. ${ }^{17}$ In five of the six group A subjects $\mathrm{k}$ fell around the upper limits of the normal range, while Vo/Vmax was at or below the lower limit of the normal range; the change in VC after bronchodilators was relatively small (mean increase of 0.481 ) but there was a small fall in $\mathrm{k}$ and rise in Vo/Vmax in the five subjects who showed significant rises in VC, bringing both parameters closer to the mean of the normal range. Thus the changes in alveolar distensibility were relatively small. While this might reflect the relatively mild impairment of airway function in group $\mathrm{A}$, our values are very similar to those of Colebatch et $a l^{28}$ in more severe asthma. As expected, there was a consistently reduced Vmax at a standard Pst(1) - that is, decreased upstream conductance-in the group A subjects with an increase in upstream conductance after bronchodilator treatment. Therefore, although some abnormalities in the PV curve are present in asthma, these are small and do not prevent the PV curve, and particularly the value of $\mathbf{k}$, being useful for distinguishing emphysema from asthma at a stage when symptoms are slight.

Because we used values of TLCO/VA to select two group $E$ subjects we cannot use the present results to assess the relative sensitivity of $P V$ curves and $\mathrm{CO}$ transfer for detecting probable emphysema. In our earlier study of intermediate alpha $_{1}$-antitrypsin deficiency however the four men with definite abnormality of $\mathrm{PV}$ curves did not have reduced values of TLCO/VA. ${ }^{7}$ Although severe reductions in TLCO/VA usually are associated with the presence of emphysema at postmortem, ${ }^{22}$ minor reductions are commonly found in smokers at an age when emphysema is rare. ${ }^{329}$ Clearly minor abnormalities in both $\mathrm{TLCO}_{\mathrm{LCO}} \mathrm{V}_{\mathrm{A}}$ and the PV curve may be found in the absence of emphysema. Further studies are required to establish how severe the abnormalities in either test must be to predict the presence of emphysema reliably, but the present results confirm that characteristic functional changes may be found in men with few or no symptoms.

This investigation was supported by a research grant from the Medical Research Council (G976/ 458). Dr R Petrik Pereira was supported by a research fellowship of CAPES, Brazil. We also thank the Julie Marmor Trust and the Chest, Heart and Stroke Association for providing technical assistance to undertake studies in the Asthma Clinic.

\section{References}

1 Gelb AF, Gold WM, Wright RP, Bruch HR, Nadel J. Physiologic diagnosis of sub-clinical emphysema. Am Rev Respir Dis 1973; 107: $50-63$.

2 Woolcock AJ, Read J: The static elastic properties of the lungs in asthma. Am Rev Respir Dis 1968; 98:788-94. 
3 Enjeti S, Hazelwood B, Permutt S, Menkes H, Terry P. Pulmonary function in young smokers: male-female differences. Am Rev Respir Dis 1978; 118:667-76.

4 Gough J. Post-mortem differences in "asthma" and in chronic bronchitis. Acta Allergol (Copenhagen) 1961 ; 16:391-9.

5 Thurlbeck WM. Chronic airflow obstruction in lung disease. Major problems in pathology. Vol 5. Philadelphia: WB Saunders, 1976:78.

6 von Nieding C, Löllgen H, Smidt U, Linde H Simultaneous washout of helium and sulphur hexafluoride in healthy subjects and patients with chronic bronchitis, bronchial asthma and emphysema. Am Rev Respir Dis 1977; 116:649-60.

7 Tattersall SF, Pereira RP, Hunter D, Blundell G, Pride NB. Lung distensibility and airway function

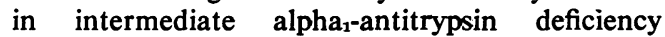
(Pi MZ). Thorax 1979; 34:637-46.

8 Tattersall SF, Benson MK, Hunter D et al. The use of tests of peripheral lung function for predicting future disability from airflow obstruction in middle-aged smokers. Am Rev Respir Dis 1978; 118: $1035-50$.

9 Fletcher CM, Peto R, Tinker CM, Speizer F. The natural history of chronic bronchitis and emphysema. An 8-year study of working men in London. Oxford: Oxford University Press, 1976.

10 Kory RC, Callahan R, Boren HG, Syner JC. The Veterans Administration-Army cooperative study of pulmonary function. 1. Clinical spirometry in normal men.Am J Med 1961; 30:24358.

11 DuBois AB, Botelho SY, Bedell R, Marshall R, Comroe JH Jr. A rapid plethysmographic method for measuring thoracic gas volume: a comparison with a nitrogen washout method for measuring functional residual capacity in normal subjects. J Clin Invest 1956; 35:322-6.

12 Leith DE, Mead J. Procedures for standardised measurements of lung mechanics. Principles of body plethysmography. National Heart and Lung Institute, Division of Lung Disease. Washington: Government Printing Office, 1974.

13 Ogilvie CM, Forster RE, Blakemore WS, Morton JW. A standardized breath-holding technique for the clinical measurement of the diffusing capacity of the lung for carbon monoxide. J Clin Invest 1957; 36:1-17.

14 Mead J. Volume displacement body plethysmograph for respiratory measurements in human subjects. J Appl Physiol 1960; 15:736-40.

15 Milic-Emili J, Mead J, Turner JM, Glauser EM. Improved technique for estimating pleural pressure from oesophageal balloons. $J$ Appl
Physiol 1964; 19:207-11.

16 Glaister DH, Schroter RC, Sudlow MF, MilicEmili J. Bulk elastic properties of excised lungs and the effect of a transpulmonary pressure gradient. Respir Physiol 1973; 17:347-64.

17 Gibson GJ, Pride NB, Davis J, Schroter RC. Exponential description of the static pressurevolume curve of normal and diseased lung. $A m$ Rev Respir Dis 1979; 120:799-811.

18 Mead J, Turner JM, Macklem PT, Little JB. Significance of the relationship between lung recoil and maximum expiratory flow. J Appl Physiol 1967; 22:95-108.

19 Goldman HI, Becklake MR. Respiratory function tests. Normal values at median altitudes and the prediction of normal results. Am Rev Tuberc 1959; 79:457-67.

20 Cherniack RM, Raber MB. Normal standards for ventilatory function using an automated wedge spirometer. Am Rev Respir Dis 1972; 106:38-46.

21 Bradley J, Bye C, Hayden SP, Hughes DTD. Normal values of transfer factor and transfer coefficient in healthy males and females. Respiration 1979; 38:221-6.

22 Burrows B, Fletcher CM, Heard BE, Jones NL, Wootliff JS. The emphysematous and bronchial types of chronic airways obstruction. Lancet 1966; 1:830-5.

23 Hogg JC, Macklem PT, Thurlbeck WM. Site and nature of airway obstruction in chronic obstructive lung disease. $N$ Engl J Med 1968; 278:135560.

24 Okubo T, Piiper J. Intrapulmonary gas mixing in excised dog lung lobes studied by simultaneous wash-out of two inert gases. Respir Physiol 1974; 21:223-39.

25 Gibson GJ, Pride NB, O'Cain C, Quagliato R. Sex and age differences in pulmonary mechanics in normal non-smoking subjects. J Appl Physiol 1976; 41:20-5.

26 Leaver DG, Tattersfield AE, Pride NB. Contributions of loss of lung recoil and of enhanced airways collapsibility to the airflow obstruction of chronic bronchitis and emphysema. J Clin Invest 1973; 52:2117-28.

27 Leiner GC, Abramowitz S, Small MJ. The vital capacity in pulmonary emphysema. Ann Intern Med 1964; 60:61-5.

28 Colebatch HJH, Greaves IA, Ng CKY. Pulmonary mechanics in diagnosis. In: de Kock MA, Nadel JA, Lewis CM, eds. Mechanisms of airways obstruction in human respiratory disease. Cape Town: Balkema, 1979:25-47.

29 Krumholz A, Chevalier RB, Ross JC. Cardiopulmonary function in young smokers. $A n n$ Intern Med 1964; 60:603-10. 